\title{
NUMERICAL AND EXPERIMENTAL INVESTIGATION OF THE METHANE FILM COOLING IN SUBSCALE COMBUSTION CHAMBER
}

\author{
Y. Daimon ${ }^{1}$, H. Negishi ${ }^{1}$, M. Koshi ${ }^{2}$, and D. Suslov ${ }^{3}$ \\ ${ }^{1}$ Japan Aerospace Exploration Agency \\ JAXA's Engineering Digital Innovation Center (JAXA/JEDI) \\ 2-1-1 Sengen, Tukuba, Ibaraki 305-8505, Japan \\ ${ }^{2}$ University of Tokyo \\ 2-11-16 Yayoi, Bunkyo, Tokyo 113-8656, Japan \\ ${ }^{3}$ Deutsches Zentrum für Luft- und Raumfahrt (DLR) \\ Institute of Space Propulsion \\ Hardthausen 74239, Germany
}

\begin{abstract}
The characteristics of film cooling in a $\mathrm{CH}_{4} / \mathrm{O}_{2}$ subscale chamber with multiinjector elements and two kinds of film cooling slot dimensions are investigated using a calorimeter chamber in experiments and simulations, in which the finite rate chemistry with a reduced $\mathrm{CH}_{4} / \mathrm{O}_{2}$ reaction mechanism is taken into account. The computed wall heat flux and pressure distributions are compared to the experimental results, which overall show good agreement. A large slot dimension is shown to induce mixing with core flow. This mixing causes a low heat-flux distribution near face plate along with high combustion efficiency.
\end{abstract}

\section{INTRODUCTION}

The rocket engine techniques currently used for orbital transfer and space exploration are based on using mostly well established storable propellants. Because of their simple operation, these propellants have been preferred up to now. However, their significant disadvantages, such as toxicity and average performance compared to cryogenic propellants, drive to investigate the application of other propellant combinations.

Oxygen/methane is a very attractive propellant combination for this application becuse it provides a specific impulse improvement of several dozen seconds compared to storable propellants. The liquid oxygen/liquid methane 
$\left(\mathrm{LOx} / \mathrm{LCH}_{4}\right)$ combination may be said to be "space storable" (the liquid temperature is approximately $90-130 \mathrm{~K}$ depending on the tank pressure). With passive thermal protection, the methane boiling rates are significantly smaller than those for hydrogen. Another significant advantage is the absence of human health risk. For this reason, they are often considered to be "green propellants." Therefore, an essential part during the investigations last decades focuses on the methane application for the in-space propulsions [1-4]. One of the key aspects of advancing research is to improve our knowledge of the heattransfer processes and cooling methods in the combustion chamber, which is mandatory for engine design. The intended thermal design concepts include film cooling as one of the favorable cooling methods. Film cooling has significant advantages: high efficiency, simple thrust chamber construction, and relatively low pressure drop. These effects make the use of film cooling attractive, even if a certain decrease in propulsive performance has to be expected.

This paper presents a numerical analysis of the film cooling performance in a $\mathrm{CH}_{4} / \mathrm{O}_{2}$ subscale combustion chamber, as well as the results of the experimental investigation used for the validation of the numerical tools. In the previous numerical works $[5,6]$, the coaxial injector of $\mathrm{CH}_{4}$ and $\mathrm{O}_{2}$ was simplified to simulate the heat flux to the thrust chamber wall of the $\mathrm{CH}_{4} / \mathrm{O}_{2}$ subscale combustor. The near injector plate phenomena were neglected, and equilibrium combustion products were injected into the chamber at the adiabatic flame temperature. Therefore, a ratio between film cooling velocity and coaxial injector jet velocity is different from an actual condition. This ratio is important for the shear between film and the coaxial injector jet and, then, the cooling efficiency. The difference of heat flux for slot dimensions was very small in the previous works because the coaxial injector jet velocity was different from the actual condition. In addition, the heat-flux distributions near the face plate in the cases without film cooling could not be recreated. The investigation presented here accurately models the configuration of the coaxial injectors and provides detailed information about the cooling film and thermal load distribution on the hot inner surfaces of the combustion chamber. The investigation focuses on the interaction of the reacting flow with film cooling in the cylindrical part of the combustion chamber near the injector head. Because of the extremely complicated flow phenomena in this area in combination with intensive chemical reactions, the problem is partially simplified injecting gaseous oxygen and methane in experiment. Numerically, the simulation does not need to take into account phase change and real gas effect for this simplified injection. These investigations aim to provide a significant contribution to the understanding of the thermal transfer processes and to validation of the design tools. The simulation code in this study had been validated by the experimental heat flux data in actual $\mathrm{H}_{2} / \mathrm{O}_{2}$ thrust chambers with single and multiinjections [7-9]. For this simulation, the chemical reaction mechanisms of $\mathrm{CH}_{4} / \mathrm{O}_{2}$ also need to be 
confirmed using this validation. However, the numbers of species and reactions of $\mathrm{CH}_{4} / \mathrm{O}_{2}$ detailed chemical reaction sets are relatively large. Therefore, the authors reduce the number of species in the original $\mathrm{CH}_{4} / \mathrm{O}_{2}$ reaction mechanism for this study as will be explained later in this paper and apply it in this simulation.

\section{EXPERIMENTAL AND COMPUTATIONAL SETUP}

\subsection{Experimental Setup}

For the experimental part of the investigations, the DLR subscale combustion chamber model "B" was used (Fig. 1). This combustion chamber was especially designed to study the heat transfer to the wall and the influence of different design solutions on the thermal loads. The combustion chamber has a 50-millimeter interior diameter and consists of five 50-millimeter length cylindrical segments with a separate water cooling supply. The cooling is realized via a row of cylindrical channels in each segment. Input and output collectors provide a uniform mass flow rate through all the cooling channels.

For the determination of the thermal loads, a calorimetric method has been applied. This method delivers averaged heat fluxes derived from calorimetric measurements for each test segment. Precise temperature and pressure measurements in the cooling water inlet and outlet allow the determination of the

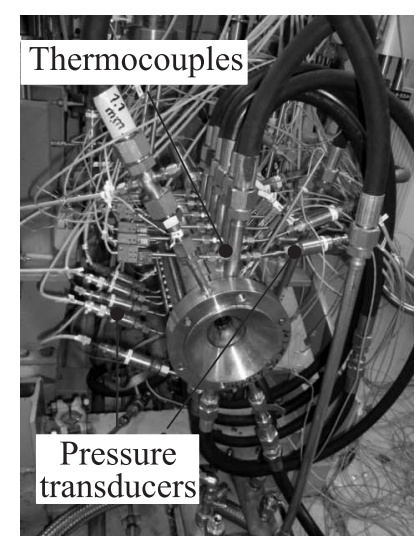

Ring slot of the film injector

$h_{\text {slot }}=0.46$ and $1.0 \mathrm{~mm}$

\section{Injector head Film injector Input collector}

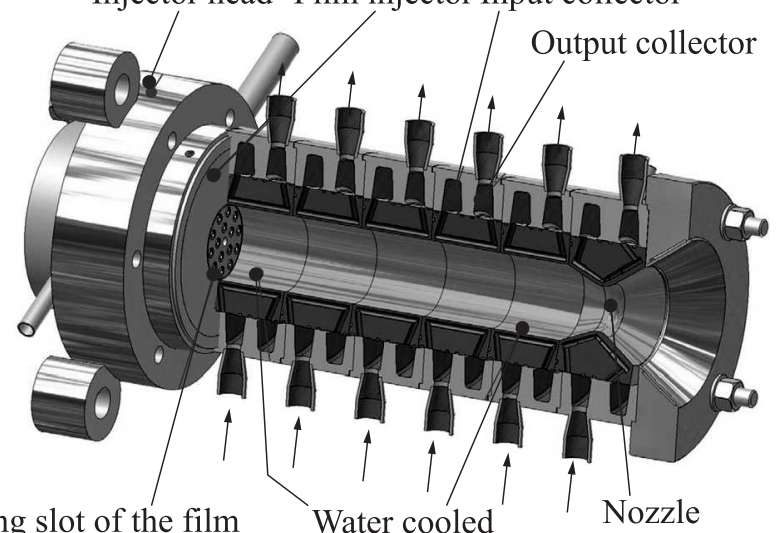

Water cooled

cylindrical segments

$D=50 \mathrm{~mm}, L=50 \mathrm{~mm}$

Figure 1 DLR subscale combustion chamber model "B" 
increasing coolant enthalpy in the cooling system of each segment and, accordingly, its averaged heat flux:

$$
\dot{q}=\dot{m}_{\mathrm{H}_{2} \mathrm{O}} \frac{h_{\text {output }}\left(T_{\text {output }}, P_{\text {output }}\right)-h_{\text {input }}\left(T_{\text {input }}, P_{\text {input }}\right)}{A}
$$

where $\dot{q}$ is the heat flux; $\dot{m}_{\mathrm{H}_{2} \mathrm{O}}$ is the coolant mass flow; $h_{\text {output }}\left(T_{\text {output }}, P_{\text {output }}\right)$ is the enthalpy at the output of the cylindrical segment as a function of temperature and pressure in the output manifold; $h_{\text {input }}\left(T_{\text {input }}, P_{\text {input }}\right)$ is the enthalpy at the input into the cylindrical segment as a function of temperature and pressure in the inlet manifold; and $A$ is the area of the hot gas surface single segment.

The surface temperature is calculated from the heat flux and from measurement temperatures, from thermocouples positioned within the hot gas-wall in a depth of $1 \mathrm{~mm}$ using a simple linear approximation.

Using the calorimetric technique, the integral heat load in the segments could be determined with good accuracy. However, the local heat flux could not be resolved. Therefore, the presented experimental results show the average heat flux for each test segment. The measurement error has been estimated by using the error propagation law as ca. $\pm 5 \%$ for the heat flux density and ca. $\pm 15 \mathrm{~K}$ for the surface temperature at current thermal loads.

The injector head (Fig. 2) contains central igniter and 15 coaxial injector elements. The injector elements are positioned on two different pitch circles. Five injector elements are arranged in the inner row and ten injector elements in the outer row. The elements form 5 identical triangles. This pattern design is intended to provide a uniform distribution of the local combustion zones and correspondingly ensures circumferentially uniform thermal loads on the hot gas surface of the combustion chamber wall. Film injection is implemented between the injector head and the measurement segment. The film injection element with a ring injection slot was implemented between the injector head and the first measurement segment. In the presented test row, two slot dimensions, 0.46 and $1.0 \mathrm{~mm}$, were employed.

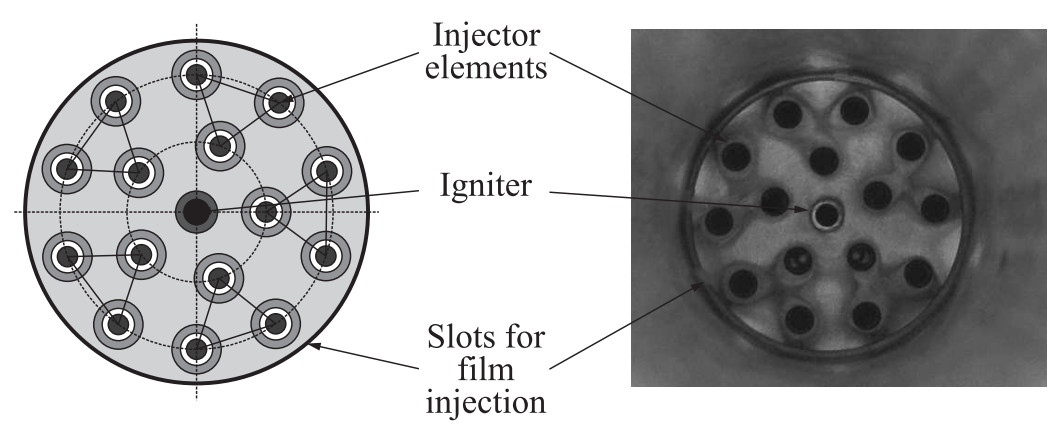

Figure 2 Injector head and film injector 

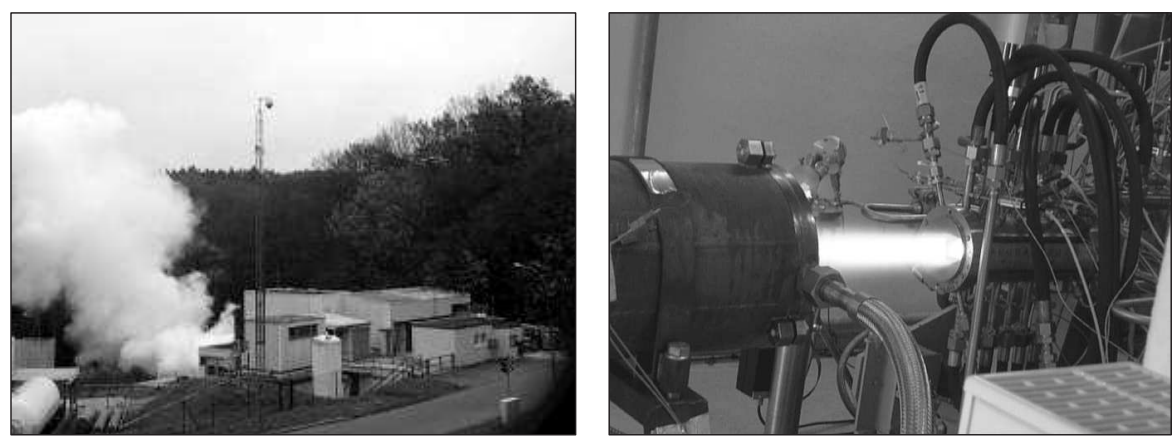

Figure 3 Tests at research test bench P6.1

Table 1 Inlet Conditions

\begin{tabular}{lccc}
\hline \multirow{2}{*}{ Conditions } & \multicolumn{3}{c}{ Slot dimension, $\mathrm{mm}$} \\
\cline { 2 - 5 } & 0.46 & 1.00 & 0 \\
\hline Fuel $\left(\mathrm{CH}_{4}\right)$ mass flow rate, $\mathrm{kg} / \mathrm{s}$ & 0.083 & 0.083 & 0.084 \\
Fuel $\left(\mathrm{CH}_{4}\right)$ temperature, $\mathrm{K}$ & 267.0 & 263.8 & 262.6 \\
Oxidizer $\left(\mathrm{O}_{2}\right)$ mass flow rate, $\mathrm{kg} / \mathrm{s}$ & 0.28 & 0.28 & 0.28 \\
Oxidizer $\left(\mathrm{O}_{2}\right)$ temperature, $\mathrm{K}$ & 272.8 & 268.6 & 270.6 \\
Film $\left(\mathrm{CH}_{4}\right)$ mass flow rate, $\mathrm{kg} / \mathrm{s}$ & 0.073 & 0.073 & 0 \\
Film $\left(\mathrm{CH}_{4}\right)$ temperature, $\mathrm{K}$ & 281.0 & 279.0 & - \\
Velocity ratio (film velocity / fuel velocity) & 1.08 & 0.50 & - \\
\hline
\end{tabular}

The test series has been performed at the Research Test Facility P6.1 (Fig. 3) at the Institute for Space Propulsion, German Aerospace Center (DLR). This test facility enables investigations with methane at typical rocket engine operating conditions. The combustion chamber operates with gaseous oxygen and gaseous methane at ambient temperature. For film cooling, gaseous methane at ambient temperature was used.

The tests used as a reference case for the validation numerical tool have been performed at a combustion chamber pressure 1.2 $\mathrm{MPa}$ with film cooling and 1.0 MPa without film cooling. The mixture ratio was 3.4 in all cases. The correspondent inlet conditions are shown in Table 1. These parameters have been used as boundary conditions for the numerical simulation.

\subsection{Computational Setup}

The numerical simulations presented in this paper are carried out using the density-based solver CRUNCH CFD, which was developed by Combustion Re- 


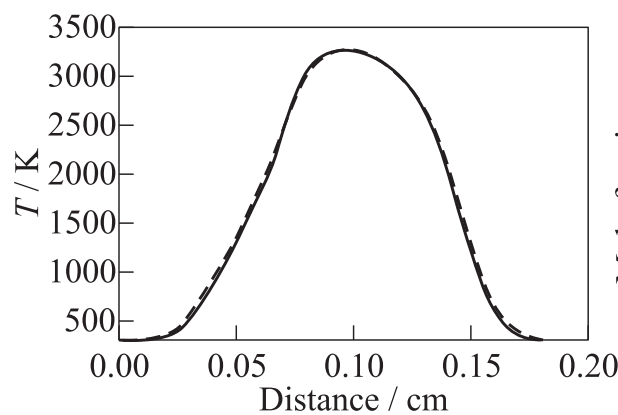

(a)

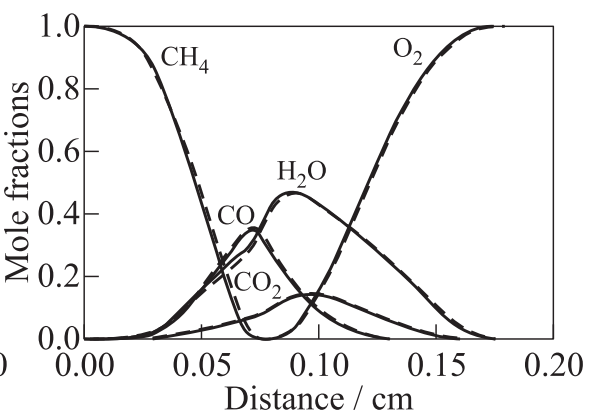

(b)

Figure 4 Temperature $(a)$ and mole fractions $(b)$ in opposite counterflow flame at $p=10 \mathrm{~atm}$. The solid curves were obtained using the original mechanism $(65$ species and 337 reactions), and the dashed curves were obtained using the reduced mechanism (23 species and 90 reactions). The inlet velocities of $\mathrm{CH}_{4}$ and $\mathrm{O}_{2}$ were set to be equal to $10 \mathrm{~cm} / \mathrm{s}$

search and Flow Technology (CRAFT Tech) [10]. CRUNCH CFD is an unstructured/multielement flow solver based on a cell-vertex method $[11,12]$. The governing equations are the three-dimensional (3D) compressible Favre-averaged Navier-Stokes equations.

In the present simulation, a detailed chemistry is taken into account. The original mechanism for the high-pressure $\mathrm{CH}_{4} / \mathrm{O}_{2}$ combustion is taken from the base mechanism of the KUCRS automatic chemical kinetic mechanism generator developed by Miyoshi [13]. This mechanism consists of 65 chemical species with 337 elementary reactions and has been well validated against a large quantity of high-pressure shock tube data and laminar flame velocities. The mechanism is reduced by using DRG-EP (Directed Relation Graph with Error Propagation) method [14] implemented in CHEMKIN-PRO [15]. The opposite counterflow flame is used as the target system of this reduction. It is noted that a more severe reduction is possible for the diffusion flame than for the premixed combustion system. The resulting reduced mechanism contains 23 species with 90 reactions. Figure 4 shows a comparison of the temperature and concentration profiles obtained by the original and reduced mechanism. The accuracy of the reduced mechanism for the diffusion flame is quite satisfactory. The combustor of the coaxial injectors, which is the computational object, has the typical diffusion flames. The velocity ratio between the fuel and oxidizer in this coaxial injector are almost unity. Therefore, this opposite counterflow flame with low velocity is consistent physics with the flame of the real combustor.

The inviscid fluxes are calculated using a second-order linear reconstruction procedure based on a total variable diminishing scheme. The viscous fluxes 


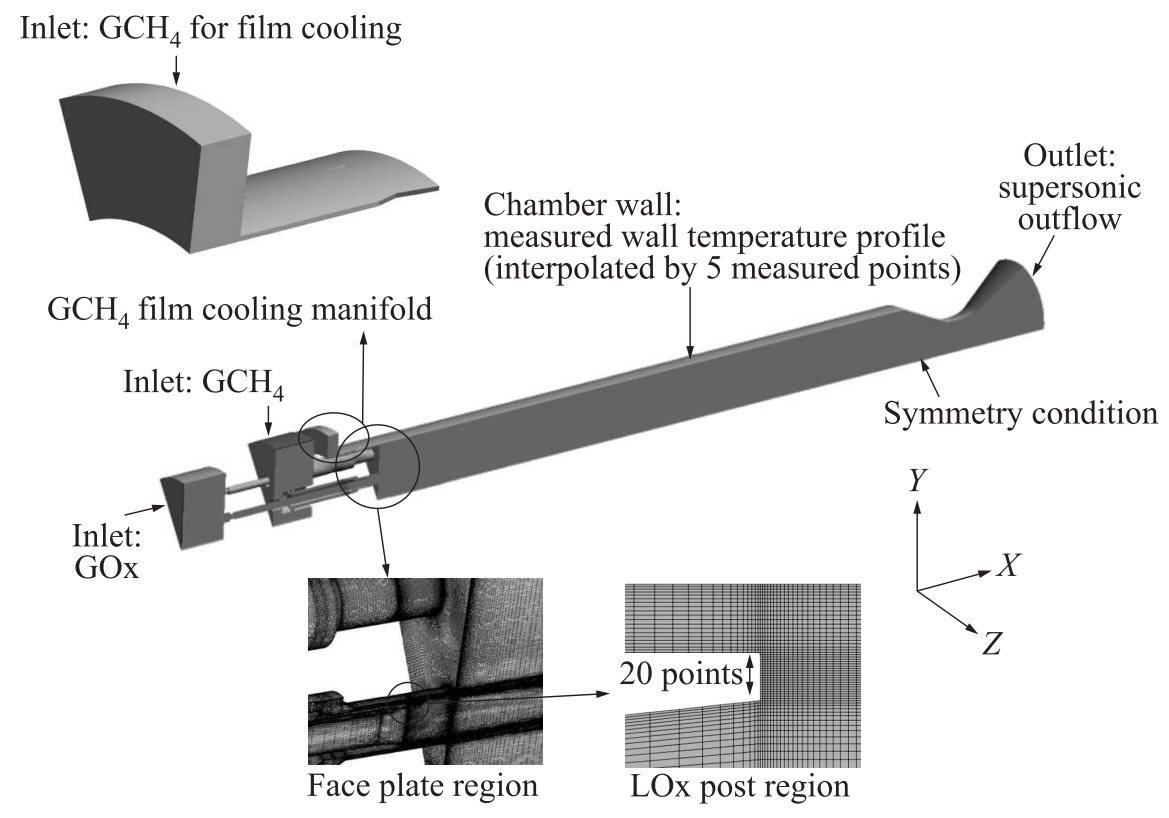

Figure 5 Computational grid and boundary conditions for sub-scale thrust chamber with multi-injector elements

are computed by estimating the gradients at the cell faces. The standard high Reynolds number $k-\varepsilon$ model is used for turbulence modeling with near-wall treatment based on a damping function [16]. For time integration, the implicit solution procedure is employed, allowing for Gauss-Seidel or generalized minimal residual (GMRES) solver options with a preconditioning matrix using a distanceone neighbor bandwidth [12]. For the combustion model, the laminar finite rate model with the reduced chemical reaction set of $\mathrm{CH}_{4} / \mathrm{O}_{2}$ is selected because the accuracy of species distribution in the boundary layer is important for the prediction of the wall heat flux.

The 3D computational domain with the boundary conditions is shown in Fig. 5. Close-up views of the computational grid for several regions are also shown. The number of computational grid points is approximately 12.5 million, in which the $Y^{+}$of the near-wall grid is about 2.0 along the entire length. In this case, a symmetry condition is also assumed in the circumferential direction and only a 36 degree region of the chamber is simulated, in which one and a half injector elements are considered in the computational domain. For the boundary conditions, the supersonic outflow condition is imposed on the nozzle outlet and the mass flow rate and static temperature of $\mathrm{CH}_{4}$ and $\mathrm{O}_{2}$ are specified at the inlet boundaries for each fluid; hence, the chamber pressure is a result of the 
computation and can be compared to the experimental value. A no-slip and isothermal wall with the temperature distribution estimated from experiments is assumed as the water-cooled wall. For the other walls, no-slip and adiabatic conditions are imposed.

Under these computational setups, computational time is about 14 days with 500 cores in JAXA's Super Computer System (JSS).

\section{VALIDATION}

The simulation code is validated using the experimental data of the averaged heat flux in the circumferential direction and the chamber pressure for the subscale combustion chamber with and without film cooling. For these validations, both of the coaxial injector and the film cooling slot in three dimensions should be taken into account because the shear between film cooling and coaxial jet decides the film live. To realize the validation of combustion pressure distributions in the combustion chamber, one cannot use the combustion gas instead

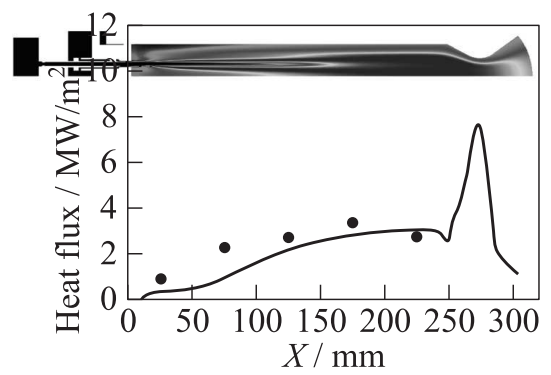

(a)

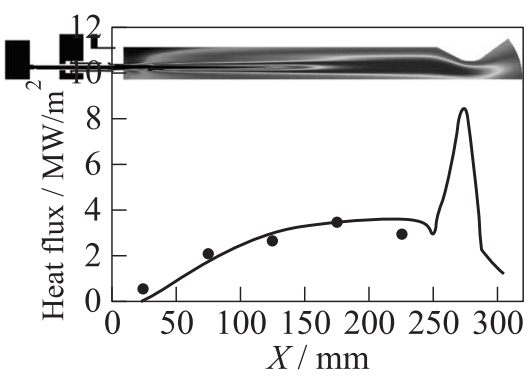

(b)

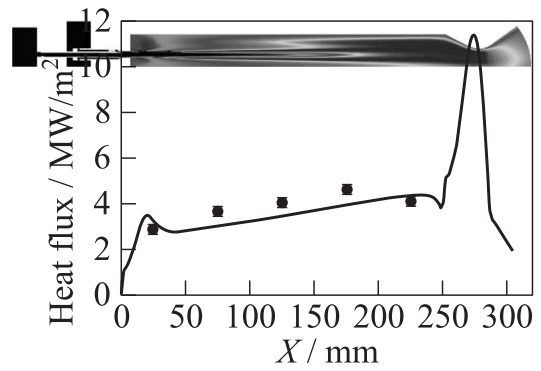

(c)

Figure 6 Averaged heat flux in circumferential direction: (a) 0.46-millimeter slot; (b) 1.00-millimeter slot dimension; and (c) no film cooling. Signs refer to experiments and curves to CFD 
of the actual coaxial injector configuration, which was proposed in the previous works $[5,6]$.

Figure 6 shows the circumferentially averaged heat fluxes for the experiment and simulation. Figures $6 a$ and $6 b$ correspond to the film cooling cases with 0.46 and $1.00 \mathrm{~mm}$, respectively. The experimental data increase gradually from 0 to $200 \mathrm{~mm}$. The most downstream point in the experimental data is slightly lower than the heat flux at $x=170 \mathrm{~mm}$. The simulation result has the same tendency in the cylindrical part of the thrust chamber. The heat flux increases gradually in the cylindrical part and is concave at the nozzle inlet. The largest peak appears around the throat. The simulation results show good agreement with the experimental data except for the data at $80 \mathrm{~mm}$ in the case of the 0.46 -millimeter slot dimension. Figure $6 c$ shows the heat flux distributions in the case without film cooling. The experimental data increase gradually from 0 to $200 \mathrm{~mm}$ in the same manner as the cases with film cooling. However, the heat flux near the face plate in the experimental data is higher than the cases with film cooling, obviously. The most downstream point in the experimental data is slightly lower than the heat flux at $x=170 \mathrm{~mm}$ in the same manner as the cases with film cooling. The simulation result has the same tendency in the cylindrical part. Near the face plate, the heat flux has a steep slope. This corresponds to the flame attaching to the chamber wall. The small peak is the characteristic of Reynolds-averaged Navier-Stokes (RANS) simulation and is not physical phenomena. The simulation results show good agreement with the experimental data. The cooling efficiency will be discussed in section 4 .

Temperature contours are shown at the same size as the heat flux graphs in Fig. 6. In Figs. $6 a$ and $6 b$, there are thick thermal boundary layers near the thrust chamber wall because of the $\mathrm{CH}_{4}$ film cooling gas in the film cooling cases. The high-temperature region indicates the flame between the $\mathrm{CH}_{4}$ and $\mathrm{O}_{2}$ injector flow. These characteristics are almost the same in all cases.

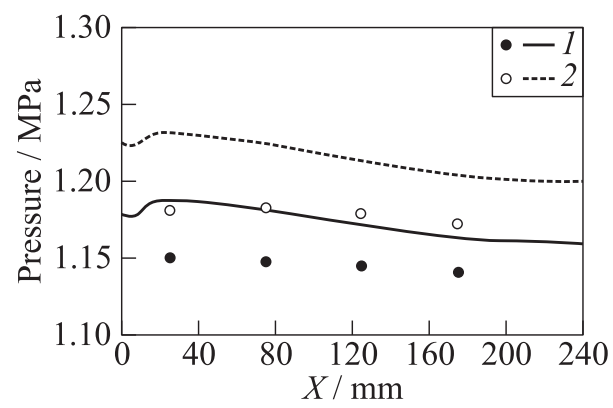

Figure 7 Pressure distributions in chamber: $1-0.46 \mathrm{~mm}$; and $2-1.00 \mathrm{~mm}$. Signs refer to experiments and curves to CFD 
Figure 7 shows the static pressure distributions in the thrust chamber. The simulated results are slightly higher than those of experimental data in all regions. The pressure decreases gradually downstream in both of the experimental and simulation results. The pressure in the case of the 1.00-millimeter slot dimension is higher than that of the 0.46-millimeter slot dimension in the experimental data. This tendency can be reproduced in the simulation results.

\section{DISCUSSIONS}

\subsection{Effect of Slot Dimension for on Rocket Performance}

The effects of the slot dimension on the heat flux, cooling efficiency, and the efficiency of the characteristic exhaust velocity are discussed.

Figure $8 a$ shows a comparison of the wall heat fluxes with the 0.46- and 1.00millimeter dimensions. The heat flux with the 1.00-millimeter dimension in the experimental data is lower than that with $0.46 \mathrm{~mm}$ in $x=0 \ldots 120 \mathrm{~mm}$. On the other hand, this magnitude relation is reversed for $x=120 \ldots 240 \mathrm{~mm}$ in the experimental data. This inversion of magnitude relation for the heat flux with 0.46 and $1.00 \mathrm{~mm}$ can be reproduced in the simulation results, although the point of this inversion is $x=40 \mathrm{~mm}$.

Figure $8 b$ shows the net heat flux reduction (NHFR). The definition of NHFR is as follows:

$$
\mathrm{NHFR}=1-\frac{\dot{q}_{\text {film }}}{\dot{q}_{0}}\left(\frac{P_{\mathrm{CC} 0}}{P_{\mathrm{CC} \text { film }}}\right)^{0.8}
$$

where $\dot{q}_{\text {film }}, \dot{q}_{0}, P_{\text {CCfilm }}$, and $P_{\mathrm{CC} 0}$ are the heat flux in the case with film cooling, heat flux in the case without film cooling, combustion chamber pressure in

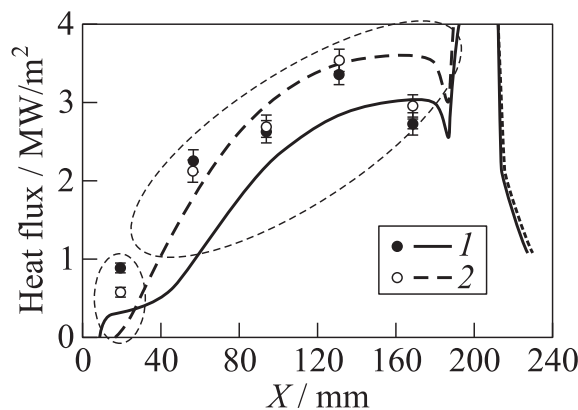

(a)

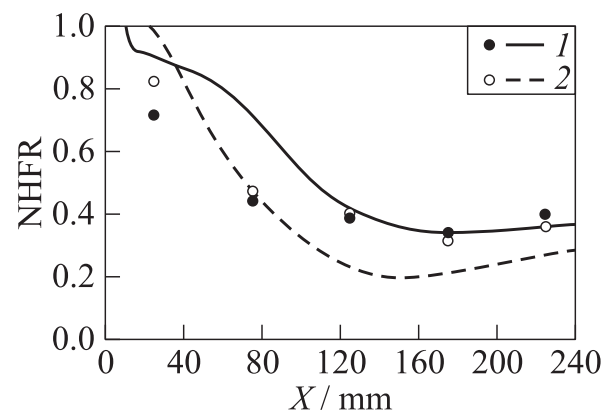

(b)

Figure 8 Heat flux $(a)$ and NHFR $(b)$ distributions: $1-0.46 \mathrm{~mm}$; and $2-1.00 \mathrm{~mm}$. Signs refer to experiments and curves to CFD 


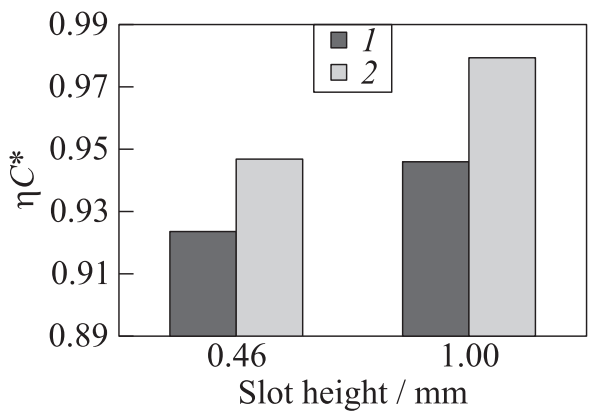

Figure 9 Characteristic velocity: $1-$ experiments; and $2-\mathrm{CFD}$

the case with film cooling, and combustion chamber pressure in the case without film cooling, respectively. The magnitude relation of NHFR with the 0.46and 1.00-millimeter dimensions is in the same manner as the heat flux as shown in Fig. 8a. The simulation results reproduce the magnitude relation of NHFR in experiment.

Figure 9 shows the efficiencies of the characteristic exhaust velocity $\left(\eta C^{*}\right)$ in the cases of the 0.46 - and 1.00-millimeter slot dimensions. The simulation results are always higher than those of the experimental data. The value of $\eta C^{*}$ in the case with the 1.00-millimeter slot dimension is higher than that in the case with the 0.46-millimeter slot dimension. However, the total mass flow rates in the setup between the 0.46- and 1.00-millimeter dimensions are the same as shown in Table 1. Under these situations, one can guess that the mixing between the film cooling and the main flow in the case of $1.00 \mathrm{~mm}$ is better than that in the case of $0.46 \mathrm{~mm}$.

\subsection{Flow Field}

Figure 10 shows the temperature distributions in the 0.46 - and 1.00-millimeter cases. The high-temperature region appears between the $\mathrm{CH}_{4}$ and $\mathrm{GO}_{2}$ of the injector flow. This indicates a diffusion flame. The $\mathrm{CH}_{4}$ film cooling induces low-temperature layer near the thrust chamber wall. The temperature of the $\mathrm{CH}_{4}$ film cooling increases as the film cooling flows downstream. The difference between the 0.46 - and 1.00-millimeter cases involves the temperature distribution along the centerline. The temperature of the centerline in the case of the 0.46 millimeter slot dimension is higher than that of the 1.00-millimeter case.

The $\mathrm{CH}_{4}$ mole fraction distributions in the cross sections are shown in Fig. 11. These distributions illustrate the effect of the film cooling flow. The red parts of these distributions indicate a high mole fraction of $\mathrm{CH}_{4}$. On the other hand, the blue parts indicate $\mathrm{GO}_{2}$ or combustion gas. There is a high mole fraction of 


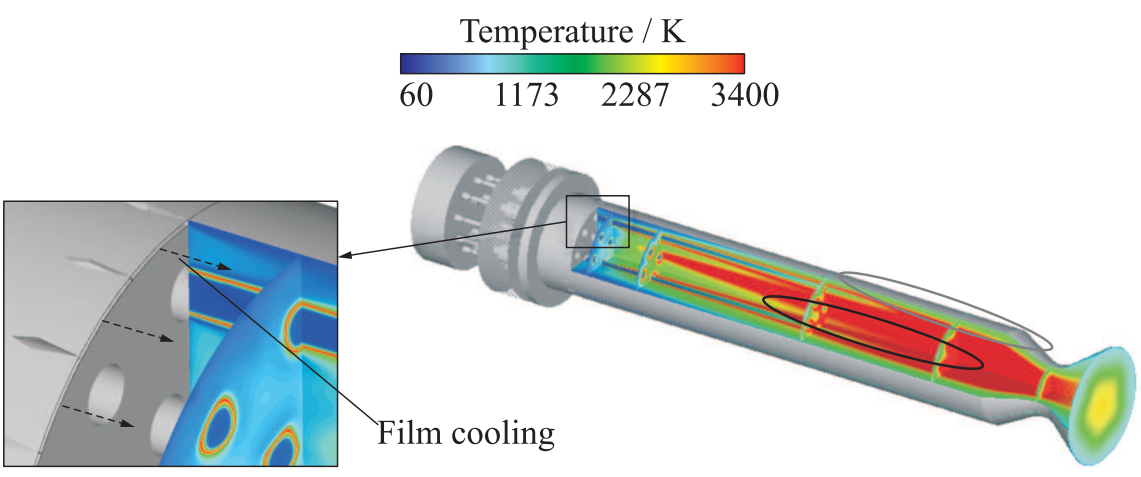

(a)

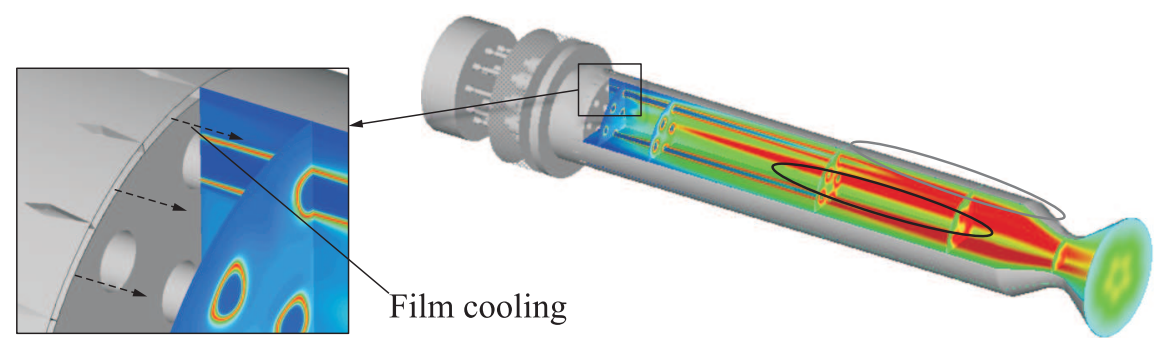

(b)

Figure 10 Temperature distributions for different slots: (a) $0.46 \mathrm{~mm}$; and (b) $1.00 \mathrm{~mm}$

$\mathrm{CH}_{4}$ near the wall because of the $\mathrm{CH}_{4}$ film cooling flow. This high mole fraction corresponds to the low temperature near the wall as shown in Fig. 10. The $\mathrm{CH}_{4}$ mole fraction in the 1.00-millimeter slot dimension case throughout the cross section $x=10 \mathrm{~mm}$ is higher than that in the 0.46 -millimeter slot dimension. At $x=40$ and $140 \mathrm{~mm}$, the $\mathrm{CH}_{4}$ mole fraction for the 0.46 -millimeter slot dimension case near the centerline is lower than that of the 1.00-millimeter case. The effect of the film cooling flow in the case of the 0.46 -millimeter slot dimension appears near the centerline of the thrust chamber, unlike the case of the 1.00-millimeter slot dimension. Figure 12 shows the averaged $\mathrm{CH}_{4}$ mole fraction distributions in the cross section. The $\mathrm{CH}_{4}$ mole fraction decreases along the $x$ direction by the reaction. The $\mathrm{CH}_{4}$ mole fraction for the $1.00 \mathrm{~mm}$ case is higher than that for $0.46 \mathrm{~mm}$ in $x=0 \ldots 100 \mathrm{~mm}$, but this magnitude relation is reversed for $x=100 \ldots 300 \mathrm{~mm}$. The low $\mathrm{CH}_{4}$ mole fraction at throat is the explanation for the higher combustion efficiency in the 1.00-millimeter case.

Figure 13 shows the streamlines from the $\mathrm{CH}_{4}$ inlet of the outermost injector as green lines, the $\mathrm{CH}_{4}$ inlet of the inner injector as yellow lines, the $\mathrm{O}_{2}$ inlet 


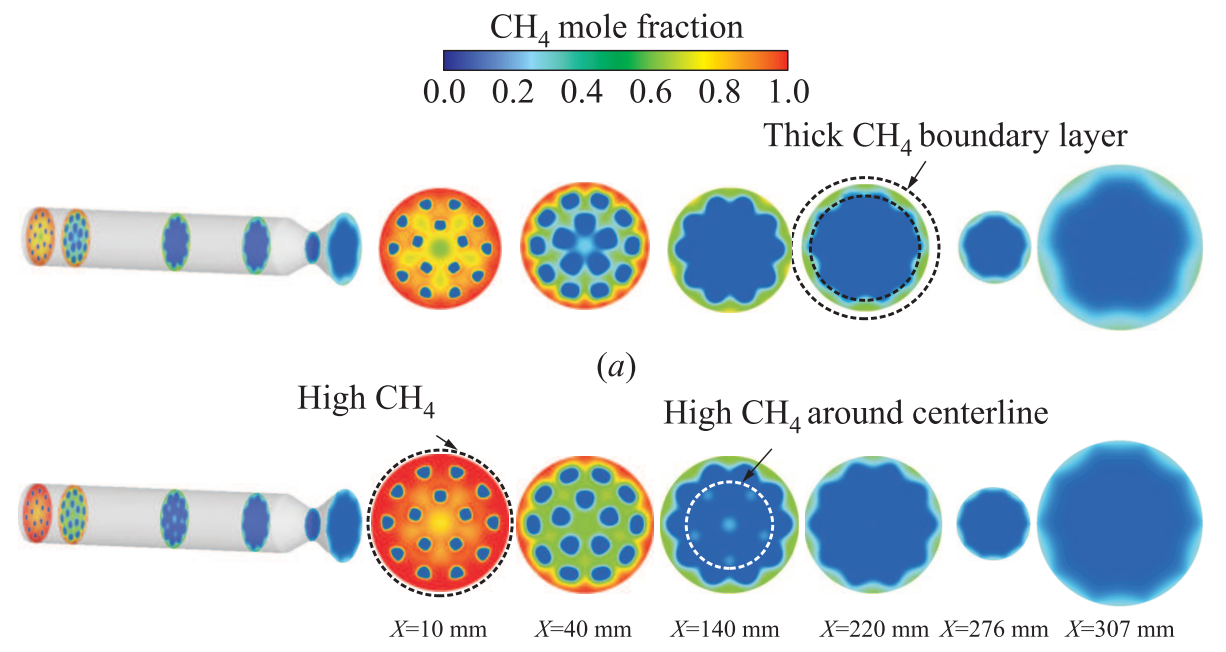

(b)

Figure $11 \mathrm{CH}_{4}$ mole fraction distributions for different film injector thicknesses: (a) $0.46 \mathrm{~mm}$; and (b) $1.00 \mathrm{~mm}$

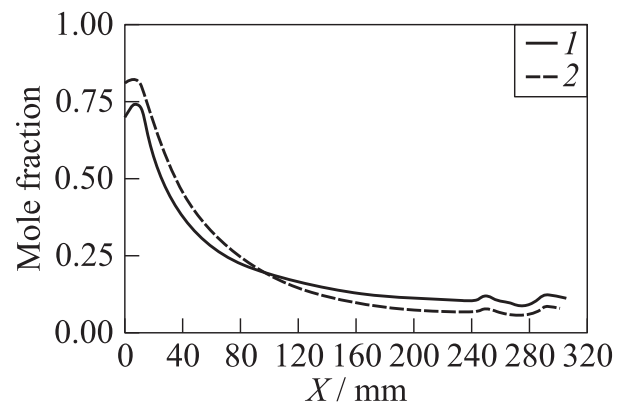

Figure 12 Averaged $\mathrm{CH}_{4}$ mole fraction distributions in the cross section: $1-$ $0.46 \mathrm{~mm}$; and $2-1 \mathrm{~mm}$

of the injectors as red lines, and the $\mathrm{CH}_{4}$ inlet of the film cooling as light blue lines. Let examine the $\mathrm{CH}_{4}$ film cooling flow as shown by the light blue lines. The film cooling flow in the case of the 0.46-millimeter slot dimension moves along the side wall of the thrust chamber. On the other hand, in the case of the 1.00-millimeter slot dimension, the film cooling flow mixes with the core flow because the velocity of the film cooling is lower than that of the core flow. This mixing between the core and film cooling flows induces a temperature decrease and high $\mathrm{CH}_{4}$ mole fraction near the face plate as shown in Fig. 11. This low- 


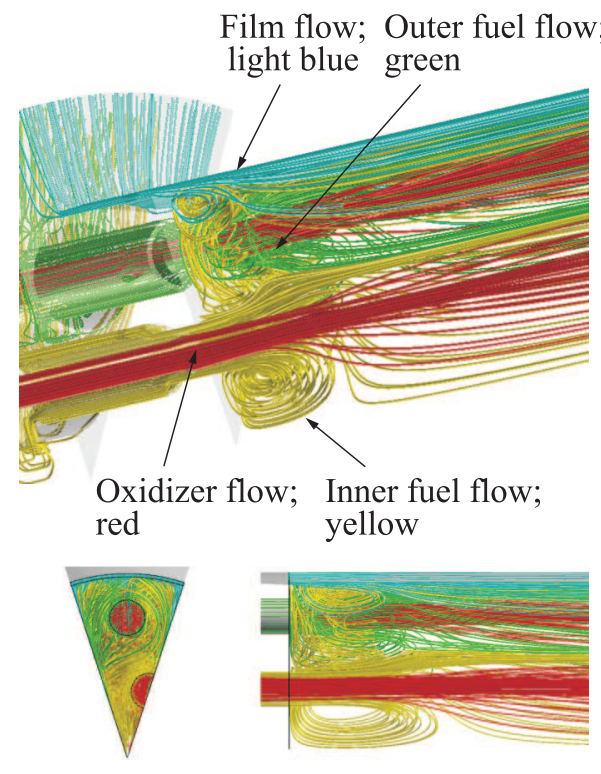

(a)
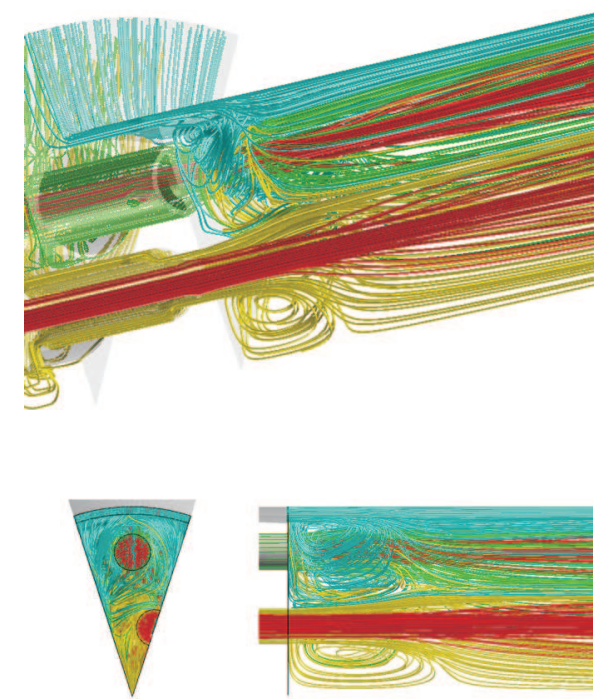

(b)

Figure 13 Streamlines for different slot dimensions: (a) $0.46 \mathrm{~mm}$; and (b) $1.00 \mathrm{~mm}$

temperature flow causes a lower heat flux near the face plate compared to the 0.46-millimeter slot dimension case as shown in Fig. $8 a$. This mixing also induces a higher heat flux downstream and higher combustion efficiency compared to the 0.46-millimeter slot dimension case as shown in Figs. $8 a$ and 9.

Generally, it can be concluded that the film cooling is more efficient for the 0.46-millimeter case than for the 1.00-millimeter case as shown in Fig. 8b. The ratio of injection velocity is almost unity between the film injection velocity and the coaxial injector jet velocity for the 0.46 -millimeter case, resulting in less shear between film and coaxial injector jet as shown in Fig. 13a. This makes the film "live longer" and induces a better cooling efficiency but at the same time, lower $\eta C^{*}$ as shown in Fig. 9.

\section{CONCLUDING REMARKS}

$\mathrm{CH}_{4} / \mathrm{O}_{2}$ multielement thrust chambers with two kinds of slot dimensions $(0.46$ and $1.00 \mathrm{~mm}$ ) for $\mathrm{CH}_{4}$ gas film cooling, which was used to perform static firing tests by DLR, were simulated using CRUNCH CFD. CRUNCH CFD was validated using the heat flux and pressure distributions of the cylindrical part 
of the thrust chamber and showed good agreement with the experimental data. The less shear for the 0.46 -millimeter case, whose ratio of injection velocity is almost unity between injection velocity and the coaxial injector jet velocity, induced a better cooling efficiency than the 1.00-millimeter case in overall. The lower speed flow of the film cooling for the 1.00-millimeter case mixed well with the coaxial injector jet. This mixing between the film cooling and the coaxial injector jet induced a low-temperature flow field and low heat flux only near the face plate. In addition, this mixing produced the high combustion efficiency.

\section{ACKNOWLEDGMENTS}

This research is a part of the DLR-JAXA Joint Research Activities. This simulation was supported by Mr. Masami Sakuno of Ryoyu Systems Co., Ltd. A part of this work was supported by JSPS KAKENHI Grant 22760160. These simulations were performed on JAXA's Supercomputer System (JSS). The authors greatly appreciate their support.

\section{REFERENCES}

1. Trinh, H. 2000. Liquid methane/oxygen injector study for potential future Mars ascent engines, A00-36389. 36th AIAA/ASME/SAE/ASEE Joint Propulsion Conference and Exhibit.

2. Craig Judd, D., S. Buccella, M. Alkema, R. Hewitt, and E. Veith. 2006. Effect of combustion process on performance, stability, and durability of a $\mathrm{LOx} /$ methane rocket engine. AIAA Paper No. 2006-1533.

3. Craig Judd, D., S. Buccella, M. Alkema, R. Hewitt, B. McLaughlin, G. Hart, and E. Veith. 2006. Development testing of a LOx/methane engine for in-space propulsion. AIAA Paper No. 2006-5079.

4. Robinson, J., Ch. Greene, and J. Stout. 2012. Regeneratively cooled liquid oxygen/methane technology development, ESA-3AF Space Propulsion Conference.

5. Suslov, D., B. Betti, T. Aichner, S. Soller, F. Nasuti, and O. Haidn. 2012. Experimental investigation and CFD-simulation of the film cooling in an $\mathrm{O}_{2} / \mathrm{CH}_{4}$ subscale combustion chamber. Space Propulsion Conference.

6. Betti, B., E. Martelli, F. Nasuti, and M. Onofri. 2012. Numerical study of heat transfer in film cooled thrust chambers. AIAA Paper No. 2012-3907.

7. Daimon, Y., Y. Ohnishi, H. Negishi, and N. Yamanishi. 2009. Combustion and heat transfer modeling in regeneratively cooled thrust chambers (co-axial injector flow analysis). AIAA Paper No. 2009-5492. 
8. Daimon, Y., H. Negishi, and N. Yamanishi. 2010. Combustion and heat transfer modeling in regeneratively cooled thrust chambers (wall heat flux validation). AIAA Paper No. 2010-6723.

9. Daimon, Y., H. Negishi, N. Yamanishi, Y. Nunome, M. Sasaki, and T. Tomita. 2011. Combustion and heat transfer modeling in regeneratively cooled thrust chambers (multi-injection flow features). AIAA Paper No. 2011-5625.

10. https://www.craft-tech.com/ (accessed 30 September, 2015).

11. Hosangadi, A., R. A. Lee, B. J. York, N. Sinha, and S. M. Dash. 1996. Upwind unstructured scheme for three-dimensional combustion flows. J. Propul. Power 12(3):494-503.

12. Hosangadi, A., et al. 1998. Hybrid, viscous, unstructured mesh solver for propulsive applications. AIAA Paper No. 1998-3153.

13. Miyoshi, A. http://www.frad.t.u-tokyo.ac.jp/ misyoshi/KUCRS/ (accessed 30 september, 2015).

14. Pepiot-Desjardins, P., and H. Pitsch. 2008. An efficient error-propagation-based reduction method for large chemical kinetic mechanisms. Combust. Flame 154:6781.

15. Reaction Workbench 15112, Reaction Design. 2011. San Diego, CA.

16. Papp, J. L., and S.M. Dash. 2001. Turbulence model unification and assessment for high-speed aeropropulsive flows. AIAA Paper No. 2001-880. 